\title{
LA VISIÓN ONTOLÓGICA DE LA MUJER Y EL HOMBRE EN EL ANARQUISMO ESPAÑOL DE LOS AÑOS TREINTA: IDENTIDAD Y GÉNERO A DEBATE
}

\author{
Alejandro Lora Medina \\ Doctor, Universidad de Sevilla \\ alora@us.es
}

\begin{abstract}
RESUMEN: Este artículo pretende analizar la visión que el anarquismo español desarrolló hacia el hombre y la mujer, tanto como género como especie en la década de 1930, época de profundos cambios políticos y sociales en España. Dicha configuración ideal tiene como antecedentes los debates desarrollados desde finales del siglo XIX que están en la base de la propia conformación del anarquismo como ideología obrerista de carácter revolucionaria. Dicho estudio forma parte de un análisis cuantitativo que muestra la defensa de una nueva ética que debía llevar a constituir un individuo totalmente emancipado de la moral tradicional. Por último, se hace énfasis en un aspecto considerado relevante como fue el peso que la tradición ejerció sobre el propio pensamiento libertario, impidiendo una extensión completa de los postulados ácratas, incluso en la propia definición de la mujer y el hombre.
\end{abstract}

Palabras clave: España, anarquismo, género, identidad.

\section{THE ONTOLOGICAL VISION OF WOMEN AND MEN IN THE SPANISH ANARCHISM OF THE THIRTIES: THE GENDER AND IDENTITY DEBATE}

ABSTRACT: This article aims to analyse the vision that Spanish anarchism developed towards men and women, both as a gender and a species in the 1930s, which was a time of profound political and social change in Spain. This ideal configuration has the debates developed since the end of the nineteenth century, which are at the base of the very conformation of anarchism as a revolutionary workers' ideology, as its precedents. This study is part of a quantitative analysis 
that shows the defence of a new ethic that should lead to constitute an individual completely freed from traditional morality. Finally, emphasis is placed on an aspect that was considered relevant, as was the weight that tradition exerted on libertarian thought itself, preventing a complete extension of the anarchist postulates, even in the very definition of women and men.

Keywords: Spain, anarchism, gender, identity.

Recibido: 17 de septiembre de 2017

Aceptado: 16 de Noviembre de 2017

\section{Introducción}

El ser humano desempeña una función central en la construcción del modelo de sociedad para el anarquismo. Dicha centralidad no se circunscribe al predominio de alguno de los sexos sobre el otro, sino que interesa el individuo en su conjunto como actor del cambio social. Esta concepción del individuo como ser se afianza en la certidumbre de la teoría de la evolución permitiendo la fusión en una única naturaleza tanto de la faceta individual como de su dimensión colectiva. Ambos sexos son contemplados como el último estadio evolutivo de un largo proceso de siglos que arranca en los primeros homínidos:

En cuanto al problema de la reproducción, éste lo involucra todo porque es el problema darwiniano de la lucha por la supervivencia de la especie y por la selección natural de cada uno de sus miembros. Es la carrera de la humanidad nacida del pitecantropos, que saliendo de las cavernas y recorriendo su camino de perfección a través de los siglos, llegará un día a producir el super-hombre, y, por consiguiente, la supermujer, y en consecuencia, una super-civilización ${ }^{1}$.

Toda acción humana ajena a una conducta ética es duramente criticada porque el individuo debe actuar conforme a la responsabilidad superior que le ha otorgado la naturaleza. En los años treinta, desde la prensa anarquista se va a incidir especialmente en la visión de la naturaleza como el estado perfecto de la creación, sinónimo de orden y equilibrio, aunque de su interior ha desaparecido la noción de Dios como ser supremo. Lo natural se entiende como aquello que es en sí y se concibe por sí, de ahí que su importancia para el anarquismo sea, en palabras de Federica Montseny, "lo que constituye el origen, el fin y el medio de toda creación cósmica" ${ }^{2}$. La creación del mundo vegetal y animal es atribuida a la acción de la natura en movimiento identificada como madre suprema y creadora. El médico naturista José Martínez Novella, en su "Letanía te-

1. Barcos, J., Libertad sexual de las mujeres. Toulouse, s.d.

2. La Revista Blanca, 192, 15 de mayo de 1931. 
rrestre" -que comienza con las palabras: "¡Yo te bendigo, Madre tierra! porque tierra es sinónimo de vida"3 - , critica que el ser humano sea incapaz de percibir el potencial creador de la naturaleza y todo lo que el hombre como especie le debe. Estos elementos llevan a valorar la concepción de la naturaleza como la emanación de una creencia de raíz panteísta con rasgos divinos, hasta el punto que Ramón Liarte, secretario de las Juventudes Libertarias de Seo Urgel durante la guerra, afirmara que los anarquistas "[...] no tenemos más dioses que los impulsos y las manifestaciones de la naturaleza [...]"4

La exaltación del moralismo ácrata persigue la creación de un hombre nuevo, emancipado y en pleno uso de sus cualidades naturales que, por encima del género y la patria se erija un ser humano atemporal, libre, racional, no sujeto a fronteras, a idiomas, ni a limitaciones culturales: "[...] Es lo que queremos ser: hombres, muy hombres. Libres, muy libres. Humanos, muy humanos. Por encima de la tierra donde nacimos, está la humanidad!" ${ }^{5}$. Bajo esta cosmovisión, el hombre es el responsable final del éxito o el fracaso de la sociedad: "[...] ante su inteligencia se abate lo imposible; ante su brazo brota la ciudad grande y hermosa; la campiña fértil y exuberante; la máquina creadora de las más bellas utopías ¡que orgullo es ser hombre!"”. El individuo se erige así en el centro del proyecto ácrata en una especie de resurgir del antiguo espíritu humanista: "Yo soy anarquista por que (sic) me elevo, por que (sic) camino; por que llego a las alturas del pensamiento"7 .

Las similitudes entre este movimiento filosófico e intelectual y el anarquismo son importantes ya que ambas corrientes cultivan el saber universal en tanto que conocimiento científico. Este espíritu crítico uniforma el código moral en el que importantes militantes como Fidel Miró, secretario regional de las JJ.LL. catalanas, detectan "concepciones humanistas". Su importancia reside en que se trata de un código moral no impuesto por ningún poder exterior, sino que se construye sobre la propia autodisciplina individual ${ }^{8}$. Esta exaltación del hombre

3. El Sembrador, 2, 29 de junio de 1930.

4. Cultura y Porvenir, 15, 11 de abril de 1937. José Álvarez Junco señalaba la existencia de dos tendencias europeas en el anarquismo decimonónico español. Una, ligada a Paul Robin que negaba el carácter matriarcal de la naturaleza desde posiciones materialistas y neomaltusianas, interpretándola como transmisora de enfermedades o catástrofes. Y la otra, defendida por Henri Zisly y Émile Gravelle que sostenían que las calamidades eran consecuencia de la traición a las leyes naturales y, por tanto, la naturaleza no tenía residuo de culpa alguna. Aunque la equiparación de la naturaleza como madre que otorga dones a sus hijos no es una novedad filosófica, se detecta en el anarquismo español la primacía de la concepción de Zisly y Gravelle frente a la de Robin. Álvarez Junco, J., La ideología política del anarquismo español (1868-1910). Madrid, 1991.

5. Solidaridad Obrera, 15, 21 de marzo de 1930.

6. Solidaridad Obrera, 66, 26 de marzo de 1932.

7. Solidaridad Obrera, 163, 23 de junio de 1934.

8. Miró Solanes, F., Anarquismo y anarquistas. México D.F., 1979. El anarquista y el humanista comparten ese espíritu de examen, crítica y discusión constante. Nada escapa al análisis y a la discusión, aunque cada uno en su contexto determinado. La importancia del Humanismo como 
como especie y no como clase social persigue levantar al pueblo contra las injusticias sociales. Un pueblo que es interpretado como la emanación colectiva de la bondad de los procesos naturales pero que se encuentra sometido a la opresión de unos poderes establecidos que le impiden practicar una forma natural de autogobierno. Hombre y colectivo son para el anarquismo piezas fundamentales que le sirven para plantear su idea de sociedad desde una interpretación que intenta equilibrar lo individual y colectivo por igual ${ }^{9}$.

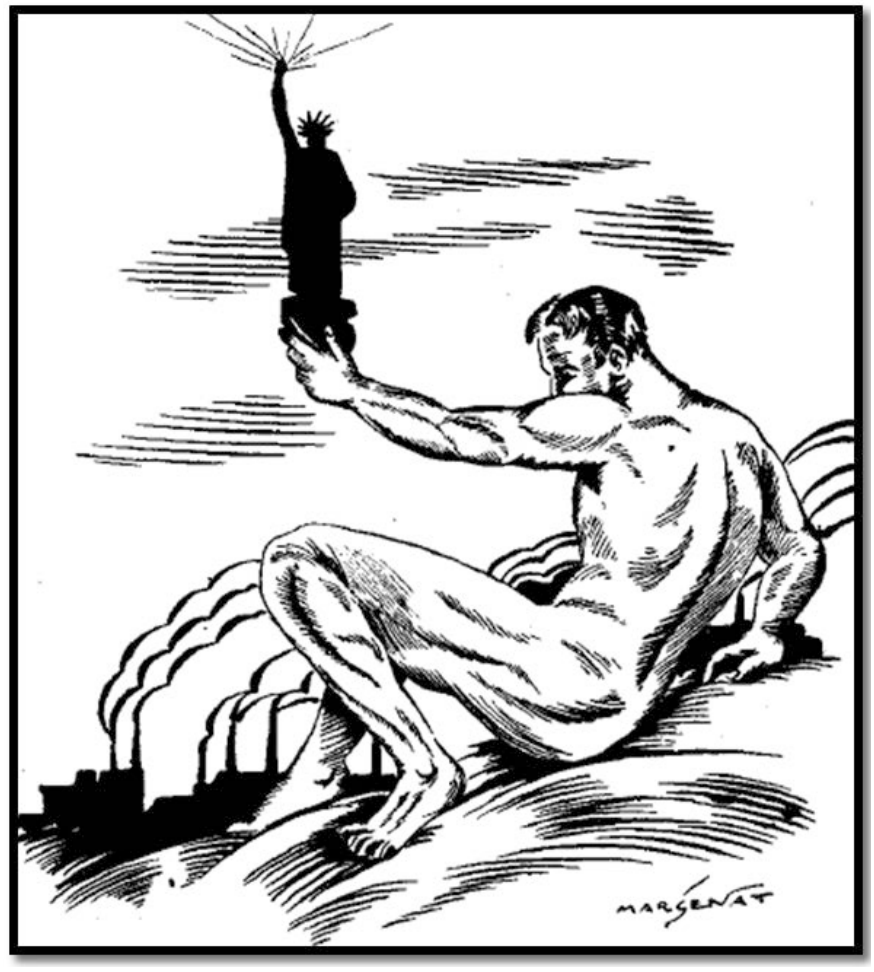

Imagen 1. Fuente: La Revista Blanca, 312, 11 de enero de 1935.

movimiento filosófico y cultural nacido en Italia hacia el siglo XIV es haberse convertido en impulsor del libre examen a partir de la crítica ideológica permitiendo la consolidación del hombre total como sujeto fundamental del estudio científico. El anarquismo se identifica con el humanismo por esta obsesión que ambos movimientos demuestran por situar el hombre en el centro de la creación. Pérez, J., Humanismo en el Renacimiento español. Madrid, 2013.

9. Nosotros, 2, 1 de noviembre de 1937; Álvarez Junco, J., "La subcultura anarquista en España: racionalismo y populismo", Culturas populares: diferencias, divergencias, conflictos: actas del coloquio celebrado en la Casa de Velázquez, los días 30 de noviembre y 1-2 de diciembre de 1983, Madrid, 1986, pp. 197-208. 


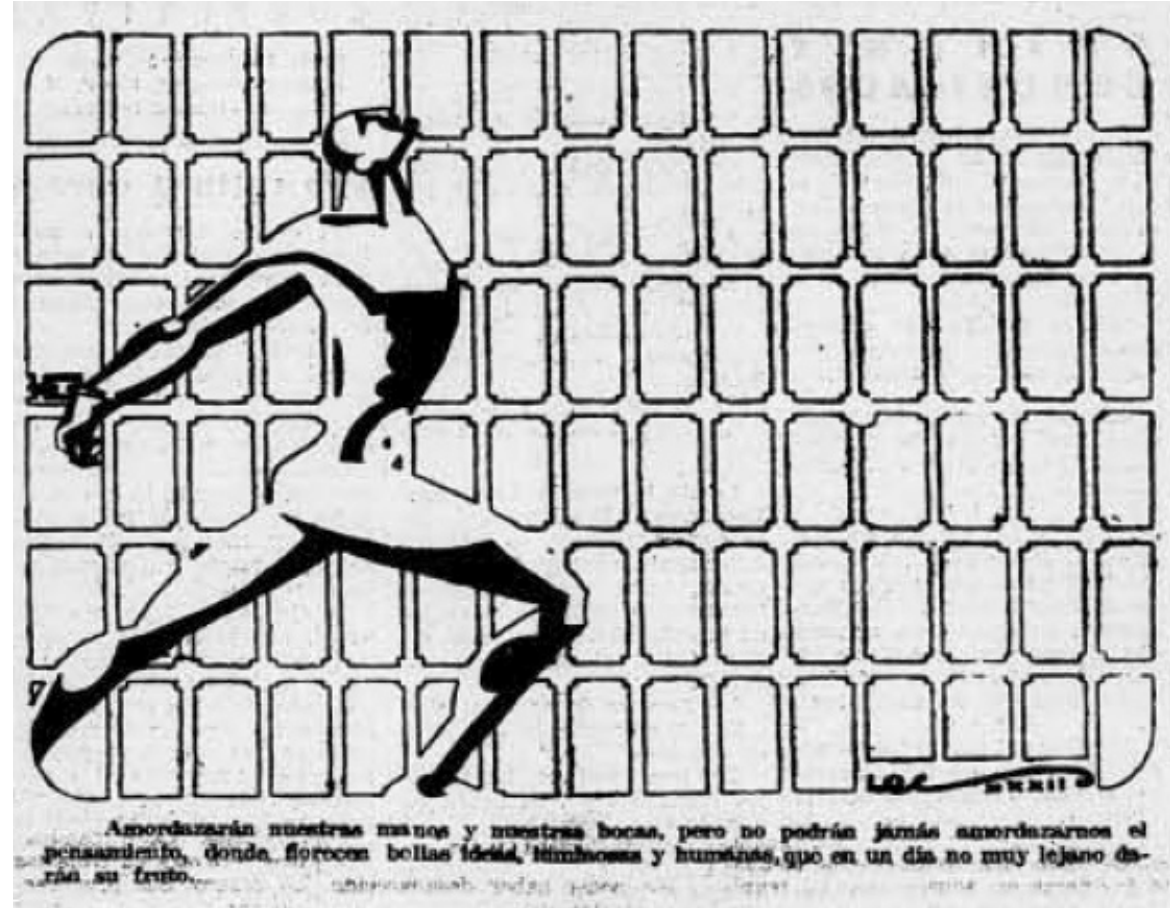

IMAGEN 2. Fuente: Solidaridad Obrera, 513, 16 de septiembre de 1932.

Esta inclinación natural a la probidad es objeto de especial interés por tratarse de uno de los fundamentos esenciales del anarquismo desde sus orígenes. A finales del siglo XIX, y por herencia del pensamiento filosófico de Rousseau a partir del mito del buen salvaje, la idea de la bondad natural alcanzó al movimiento ácrata a través de las enseñanzas de Proudhon y Bakunin, transmitidas en España por históricos como Anselmo Lorenzo, Ricardo Mella o Federico Urales. Para el anarquismo de estos años, el hombre que experimenta el progreso es un individuo que nace, tanto sin mancha como sin predisposición al mal, por lo que debe todo su desenvolvimiento moral posterior -hacia la bondad o la maldad-, a la educación recibida y al medio en el que viva. Dicho principio emana directamente de la vertiente radicalizada de la llustración que tiene en Hegel a su principal exponente. Autores como Proudhon, Teobaldo Nieva o Anselmo Lorenzo insuflarán estas ideas procedentes de Volney, Godwin, Voltaire o Tocqueville reforzando la construcción filosófica del movimiento libertario ${ }^{10}$.

10. Álvarez Junco, J., La ideología política del anarquismo español...; Joll, J., Los anarquistas. Barcelona, 1968; Arvon, H., El anarquismo en el siglo XX. Madrid, 1981; Storm, E., La perspectiva del progreso: pensamiento político en la España del cambio de siglo (1890- 
Francisco Pi y Margall, prologuista de La filosofía del Progreso de Proudhon, es uno de los principales responsables de introducir esta noción del progreso continuo de la humanidad en el anarquismo filosófico hispano. Su carácter universal supera el concepto de clase social para abarcar a toda la humanidad, de ahí que sea percibida como la ley por antonomasia. Principio que además rige el proceso del devenir histórico, siendo su principal finalidad acabar con la miseria y la pobreza ${ }^{11}$. Este carácter social y la cuestión del mejoramiento humano tiene su traslación casi intacta a la ideología libertaria, y es la esencia que se encuentra tras las palabras del periodista Salvador Cánovas Cervantes cuando afirma que la revolución española es "el proceso de desarrollo de un pueblo, de una raza y de una civilización"12.

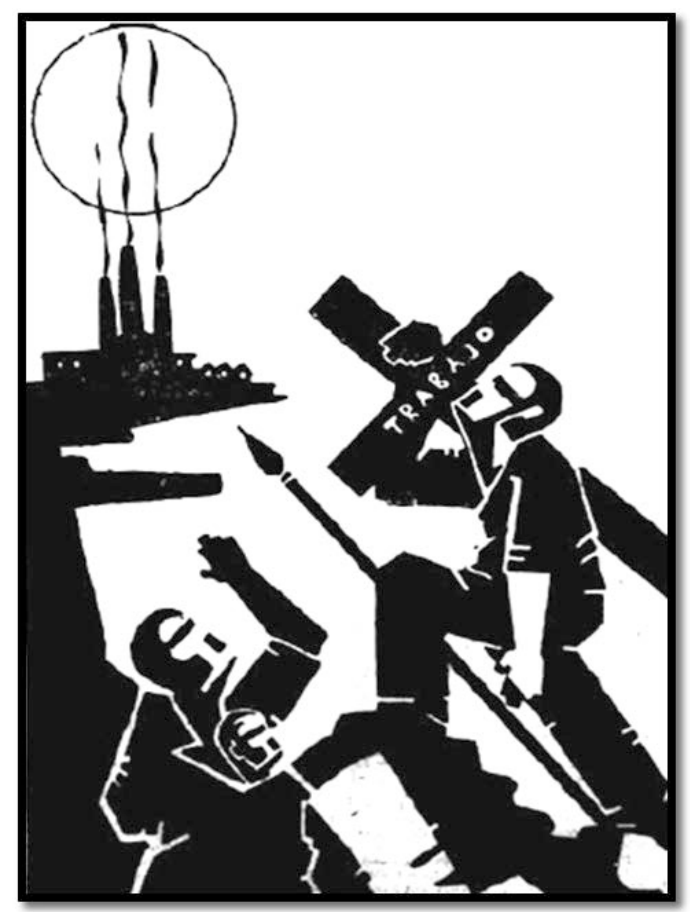

IMAGEN 3. Fuente: Solidaridad Obrera, 386, 25 de marzo de 1932.

1914). Madrid, 2001; Vallespín Oña, F., Historia de la teoría política 4. Historia, progreso y emancipación. Madrid, 2002.

11. Pi y Margall, F., La reacción y la revolución: estudios políticos y sociales. Barcelona, 1982; Anton, J., Caminal, M., Pensamiento político en la España Contemporánea (1800-1950). Barcelona, 1992.

12. Cánovas Cervantes, S., Durruti y Ascaso. La C.N.T. y la Revolución de julio (Historia de la Revolución Espaoñola). Toulouse, s.d. 
Como se observa en la imagen 3, el martirio religioso se equipara a la explotación laboral como instrumento progresivo de transformación social a través del trabajo como única fórmula posible para alcanzar la libertad anárquica de un sol que preside el mundo de la fábrica. Esa experiencia ascendente que debe recorrer el trabajador conduce a un estadio armónico de existencia común al tratado por las novelas utópicas como Locking Backward -publicada en 1933 con el título de El año 2000- que a partir de un enfoque optimista intentar convencer al lector de la cercanía del progreso. La idea de progreso se construye como un todo compuesto por ciencia y técnica que es el resultado de un proceso de perfeccionamiento constante y ascendente, tanto moral como material, que afecta al colectivo humano representado por la sociedad en su conjunto. Según la retórica ácrata, ellos son "los que avanzan al unísono del Progreso..."13, autoerigiéndose en vanguardia emancipada y revolucionaria. Progreso, adelanto científico y racionalización se unen en espacios comunes difícilmente separables porque todos se nutren de aspectos parciales. La noción de progreso aparece relacionada con el avance del conocimiento científico y las artes como causa de un proceso que conduce al hombre a trascender las creencias, especialmente relacionadas con el pensamiento religioso, y a reducir la ignorancia por medio de la educación. Este ascenso armónico provocaría necesariamente beneficios políticos y sociales, acercando gradualmente al hombre a la libertad y felicidad definitivas. La utopía del comunismo libertario se define más como el porvenir deseable donde el hombre viva en paz y armonía que como la existencia de un lugar o un sistema político determinado ${ }^{14}$.

Las continuidades doctrinales de la idea de progreso respecto al anarquismo decimonónico no son incompatibles con la teoría de la evolución debido a que la compaginación entre progreso y evolucionismo se realiza a partir de la interpretación del hombre como especie y no como individuo. José Pardo Babarro, en "Los orígenes biológicos de la humanidad", detalla el tránsito del hombre desde su animalidad hasta su definitiva humanización en un proceso de adaptación al medio y desarrollo de ciertas cualidades para la vida en sociedad. Para el sindicalista gallego estos obstáculos evolutivos son interpretados como accidentes subsanables en el futuro al alcanzar una mentalidad más desarrollada que permitiera al hombre un mejor desenvolvimiento en sociedad. Ricardo Mella y Federico Urales defienden también que la mejora constante de la sociedad en el tiempo es pareja al mejoramiento biológico de la especie humana. La capacidad racional del individuo es un don que debe emplearse correctamente, de ahí que los comportamientos irracionales, egoístas o en contra de la sociedad, sean sinónimo de un déficit en la condición humana. Dentro de esta categoría de personajes destacados por su ausencia de humanidad sobresalen los políticos, víctimas habituales

13. Vía libre, 2, 10 de octubre de 1930.

14. Estudios, 123, noviembre de 1933. 
de las críticas de los anarquistas. Victoriano Crémer Alonso dedica a Indalecio Prieto, entonces ministro de Hacienda del primer gobierno provisional de la Segunda República, las siguientes palabras: "Y tú, ex-hombre, organizador de reses lanares, insigne cuco y rey de la zancadilla, amparador de pistoleros y primer esquirol de la República [...] manda a tu ganado que se retire a las cuadras [...]"15. Así pues, la inserción doctrinal de la idea del progreso como cambio constante de la humanidad no impide la existencia de periodos de estancamiento o retroceso, por lo que si bien no se rechaza la malicia en el hombre, sí se niega su carácter natural desde el nacimiento. Esta se contextualiza dentro de unas condiciones previas, influidas por el ambiente social, que hacen que el individuo yerre su aspiración al bien ${ }^{16}$. Según esta interpretación, habría periodos en la historia donde florecen con más fuerza los ideales progresistas mientras que en otros, dominados por el autoritarismo, se ralentiza el proceso. No es casual que los periodos históricos más fructíferos sean la Antigüedad griega y la Ilustración por ser periodos de predominio de la filosofía, la razón, la lógica y la ciencia, frente al periodo tradicional relacionado con el oscurantismo religioso como la Edad Media, así como otros periodos asociados con regímenes autocráticos ${ }^{17}$.

La malicia innata se rechaza por la imposibilidad de encajarla en el concepto de progreso y se acaba culpando al medio social y al Estado de pervertir al hombre como especie, en beneficio de una casta o grupo de privilegiados. De modo que la maldad se codifica como un comportamiento antinatural y artificial propio de la sociedad capitalista. El argumento generalmente utilizado era señalar al medio social degenerado como el causante de la alienación, para no culpabilizar así al individuo, mientras la educación se convierte en el verdadero motor del cambio social y moral del individuo en sociedad. Hombres Libres, órgano confederal granadino, critica el reproche que sufrían las ideas anarquistas en tanto que su éxito requería de un individuo que se comportara de forma ejemplar: "Muchas veces he oído [...] que si bien son muy bonitas, teóricamente, nuestras ideas, hoy no son posibles en la práctica porque los hombres «somos malos»"18. El rechazo de la maldad como rasgo intrínseco a la naturaleza humana es producto de una concepción moralista que parte de la propia idea de la naturaleza como madre y que entronca con las utopías publicadas desde el siglo XVI. La equiparación dualista de valores éticos positivos -la felicidad, la igualdad o la fraternidad-con la naturaleza y la censura de valores negativos -la miseria, la desigualdad o la

15. Solidaridad Obrera, 32, 18 de julio de 1931.

16. La Colmena Obrera, 7, 12 de diciembre de 1931; Hombres libres, 58, 4 de febrero de 1938; Girón Sierra, A., “¿Hacer tabla rasa de la historia? La analogía entre herencia fisiológica y memoria en el anarquismo español (1870-1914)". Asclepio 52/2 (2000), pp. 99-118; Álvarez Junco, J., La ideología política del anarquismo español...; Joll, J., Los anarquistas.

17. Peirats, J., Glosas anárquicas (interpretación anarquista de la historia). Hospitalet de Llobregat, s.d.

18. Hombres libres, 58, 4 de febrero de 1938. 
injusticia-, ligados estructuralmente al régimen capitalista, persigue la aceptación social de la irreversible necesidad de un cambio revolucionario para acabar con el origen de la maldad ${ }^{19}$.

Parece evidente la influencia del lamarckismo en la importancia dispensada al medio ambiente como factor esencial para la configuración moral del ser humano. Jean-Baptiste de Lamarck fue uno de los principales exponentes de la teoría de la evolución al afirmar que la vida animal se había transformado desde estadios de vida inferiores. Su teoría abordaba la capacidad de los distintos organismos de adaptarse al medio ambiente de forma sucesiva para explicar así la diversidad de las especies existentes. Esta adaptabilidad evolutiva descansaría en la ley de la herencia que permitiría la transferencia de padres a hijos de las facultades necesarias para vivir en un medio cambiante. Estas ideas supondrán un cambio significativo respecto a la concepción decimonónica que señalaba la inclinación natural hacia la bondad del ser humano. El tópico del ser primitivo bueno que vive en un mundo libre y sin reglas es superado en beneficio de la idea del progreso constante de la humanidad y, por tanto, de la aceptación de que el hombre del siglo XX es el más evolucionado que haya existido $y$, por ende, el más preparado para vivir en un régimen de plena libertad ${ }^{20}$. Germinal Esgleas, en una respuesta que parece dirigida al propio Rousseau y a su buen salvaje, descarta la existencia de este pasado idílico de libertad y armonía:

Resulta una estupidez afirmar, como hace pocos días afirmaba un pobre señor, que la anarquía existe entre los pueblos salvajes. Un medio social de libertad significa siempre en el hombre un estado de conciencia individual evolucionando. La libertad que está dentro de nosotros no está detrás de nosotros, sino siempre delante de nosotros ${ }^{21}$.

El anarquismo es consciente de las limitaciones funcionales de la ley evolutiva, por lo que señala la existencia de determinadas facetas de la vida sobre las que la naturaleza no tiene influencia directa. Entre estas se encuentran los asuntos artísticos, científicos o sociales que dependerían directamente del individuo, de su formación y sus gustos. A pesar de todo, se mantiene la percepción de que el hombre sigue avanzando como especie para eliminar de su conducta una serie de comportamientos arcaicos. Los libertarios demuestran una profunda confianza en las leyes de la evolución y la ciencia como propulsoras del bienestar humano, sin olvidar la importancia que tiene la acción humana para la prosperidad, en elemento de evidente continuidad doctrinal con el anarquismo deci-

19. Rivas, M., Luz en las tinieblas. Barcelona, s.d.; Álvarez Junco, La ideología política del anarquismo español...; Horowitz, I. L., Los anarquistas. Madrid, 1982; Joll, J., Los anarquistas.

20. Moreno, J., "Lamarck necesita a Darwin: la búsqueda de intención en el estudio de la evolución y de la historia". Asclepio 61/2 (2009), pp. 233-248.

21. La Revista Blanca, 185, 15 de febrero de 1931. 
monónico. Para el pedagogo anarquista Albano Rosell el avance experimentado por la humanidad es consecuencia directa del esfuerzo humano. Por esta razón, Peirats señala que el progreso tenía dos fases complementarias, una evolutiva y otra revolucionaria. Este voluntarismo se manifiesta especialmente en relación con el concepto de revolución, entendido como acelerador del cambio social y elemento indisoluble de la idea de progreso ${ }^{22}$.

Este carácter natural hace que la revolución sea descifrada como un proceso puntual que ejecuta la propia naturaleza a través del hombre, situando en un segundo nivel de importancia el concepto de clase social, para acelerar así el ritmo de la evolución cuya meta es la Acracia: "Revolución es [...] manera con que la naturaleza humana, por medio de un acto de fuerza, se va emancipando de ella, y adelanta por el camino de la evolución general"23. Frente al evolucionismo "lento" de la naturaleza se erige, en consecuencia, un evolucionismo "rápido" del hombre para acelerar el proceso de cambio paulatino. Esta explicación plantea ciertas incoherencias formales en la práctica de un movimiento que se muestra impaciente por una transformación radical inmediata de las estructuras de poder. Si el progreso marca un camino ascendente y lineal de perfeccionamiento no haría falta la revolución para precipitar su proceso, sería cuestión de tiempo que se retornara de forma natural a un nuevo periodo de ascenso. Esto convierte al concepto de "revolución", no sólo en un factor del progreso, sino en una clara manifestación de la ley natural como hecho inexorable que no puede ser detenido: "eso sería tanto como si alguien intentase, por medios artificiales, detener el curso de la propia naturaleza en sus creaciones" ${ }^{\prime 24}$.

\section{El hombre y la mujer en el anarquismo: género vs especie}

El problema de los sexos encuentra fácil acomodo en una ideología que ensalza el potencial filosófico de la especie frente a las particularidades entre hombres y mujeres. Ambos sexos son mitades separadas de un mismo ser que necesita de su acción conjunta para triunfar en la lucha social, lo que conduce a la defensa de la igualdad entre géneros por compartir el mismo destino. La libertad del uno sin la del otro impide la libertad completa del individuo como especie. Semejante interpretación aparece reflejada en la letra de esta canción que incide en el principio básico del igualitarismo sobre el que construir filosóficamente el nuevo ser: "[...] Desnudos nacimos hombres y mujeres, igual en derechos, igual en deberes, iguales nos hizo la naturaleza, iguales seremos en la madre tierra $[\ldots]^{\prime 25}$. Esta

22. Vía libre, 3, 17 de octubre de 1936; Iniciales, 6, junio de 1935; Peirats, J., Glosas anárquicas...; Álvarez Junco, J., La ideología política del anarquismo español. Madrid, 1991.

23. La Revista Blanca, 249, 1 de octubre de 1933.

24. Cánovas Cervantes, S., Durruti y Ascaso...

25. Letra completa de la versión moderada de la canción "Arroja la bomba" compuesta durante la década de los treinta: "Defiéndete, pueblo/ contra tus tiranos/ hasta que consigas/ un mundo de 
igualdad integral, basada en la idea de que hombres y mujeres poseían la misma inteligencia natural, se hacía extensiva tanto a la vida social como a la sexual ${ }^{26}$.

La construcción de las identidades de género en el anarquismo resultó un proceso lento porque debían superarse, especialmente en el caso de las mujeres, las suspicacias y comportamientos arrastrados en la tradición sobre la imagen preestablecida de lo que era una mujer y un hombre. Las mujeres libertarias, desde el conocimiento de la cultura, iban a reclamar un espacio común pero independiente del hombre como agentes sociales autónomas y conforme al desarrollo de una conciencia femenil a partir de los años veinte y treinta. La herencia cultural feminista de décadas anteriores -representada por mujeres como Teresa Claramunt, Teresa Mañé, Isabel Vila o Louise Michel-, Ilevó al despliegue de unas prácticas sociales específicas que permitieron la construcción identitaria de un "nosotras" dentro del colectivo anarquista que reservaba un espacio propio a la sociabilidad de las mujeres. Aunque desde el anarquismo se aboga porque el hombre luche junto a la mujer por su independencia, se defiende que esta debe liderar su propia emancipación para acabar con el tópico del sexo débil a través de la politización de la mujer afianzada con los logros políticos conseguidos durante el periodo republicano ${ }^{27}$ :

La mujer tiene que vivir libre. Negarle esta libertad es condenar al hombre a ver en la que debiera ser compañera ideal, un ser marchito, enfermo, que de la sociedad comunista libertad que tiene que ser alegre, jovial, dulce, haga una sociedad triste y aburrida ${ }^{28}$.

hermanos./ Defiende tu idea/ de la tiranía,/ que tu vida sea/ en plena anarquía.// Luchemos hombres conscientes,/ defendiendo nuestra vida y dignidad;/ despejemos nuestras mentes, implantemos nuestra ansiada sociedad!// La anarquía es orden/ y amor a la ciencia,/ el funesto Estado/ es la violencia./ Rompe tus cadenas,/ no las sufras más/ si sabes romperlas/ tendrás libertad.// ¡A vivir como hombres libres;/ anarquistas, imponed vuestra moral,/ superior a la burguesa,/ destruyamos para siempre al capital!// Luchemos obreros/ por el anarquismo/ ideal hermoso/ lleno de altruismo./ Redímete pueblo/ de la autoridad,/ que mata y oprime/ con impunidad.// No ya más explotadores,/ resplandezca ya en la tierra la igualdad,/ a luchar los productores/ por un mundo de justicia y de equidad.// Desnudos nacimos/ hombres y mujeres/ igual en derechos/ igual en deberes./ Iguales nos hizo/ la naturaleza,/ iguales seremos/ en la madre tierra.// Ya no más pobres ni ricos,/ suprimamos de una vez la esclavitud./ Es misión del anarquismo/ si lo sabe defender la multitud.//. Para conocer más sobre este tema ver: De la Ossa Martínez, M. A., La música en la Guerra Civil Española. Madrid, 2011; Labajo Valdés, J., "La práctica de una memoria sostenible. El repertorio de las canciones internacionales de la Guerra Civil Española". Arbor 751 (2011), pp. 847-856.

26. Vía Libre, 30, 24 de abril de 1937; Vía Libre, 68, 5 de febrero de 1938; Gerona C.N.T., 86, 14 de septiembre de 1937.

27. Solidaridad Obrera, 18, 11 de abril de 1931; Faro, 4, 3 de diciembre de 1937; Díez, G., La mujer en la lucha social. Avellaneda, 1922; Aguado, A. M., "identidades de género y culturas políticas en la Segunda República". Pasado y Memoria 60 (2008), pp. 123-141; Nash, M., "Experiencia y aprendizaje: la formación histórica de los feminismos en España". Historia Social 20 (1994), pp. 151-172; Vega, E., "Mujeres y militancia en el anarquismo español". Spagna Contemporánea 40 (2011), pp. 67-88.

28. Solidaridad Obrera, 118, 15 de abril de 1933. 


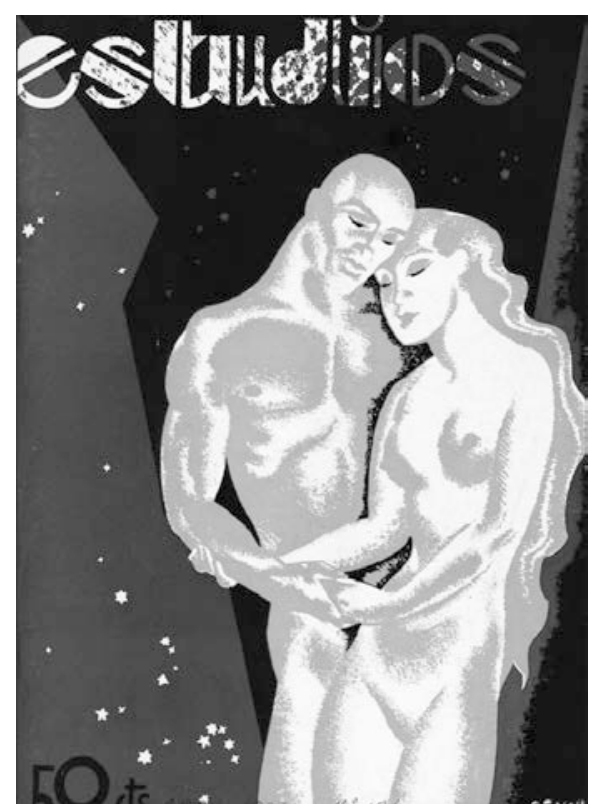

IMAGEN 4. Fuente: Estudios, 104, abril de 1932

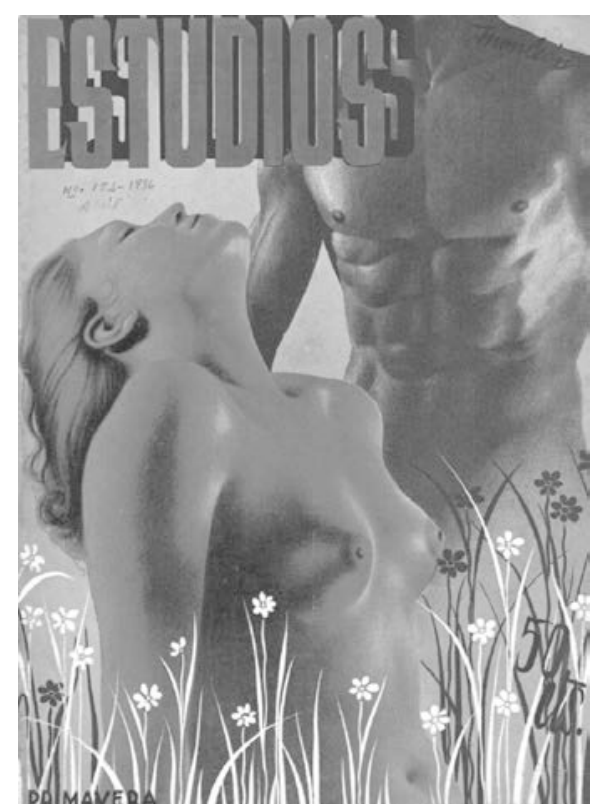

ImAGen 5. Fuente: Estudios, 152, abril de 1936

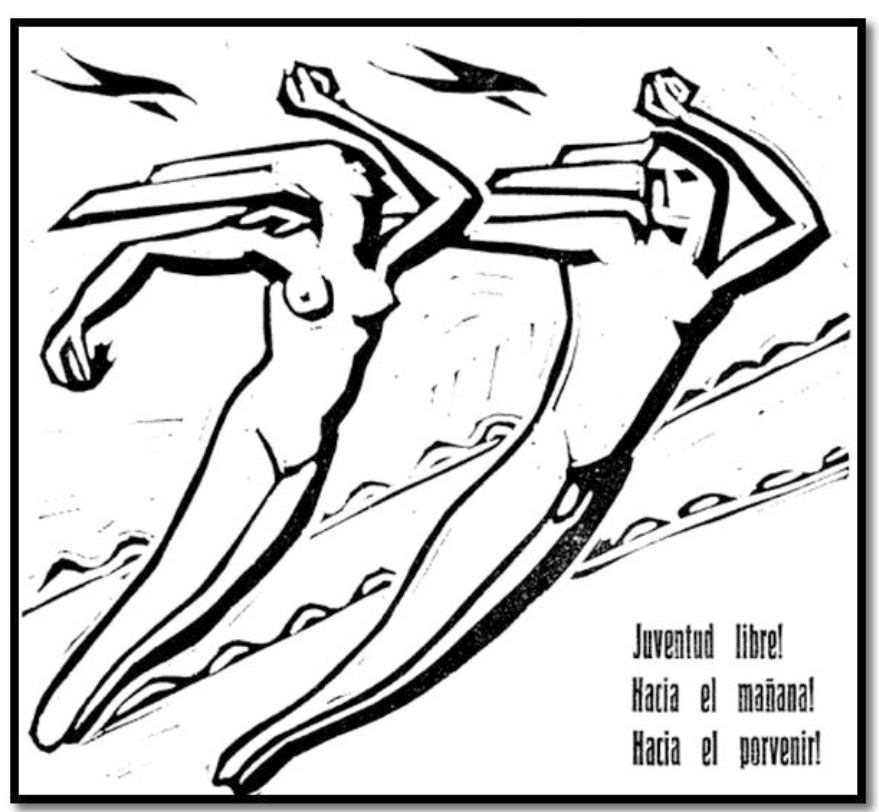

Imagen 6. A la lucha, 1, 12 de febrero de 1937. 
La existencia de una sociedad patriarcal en la que la mujer se encuentra supeditada al varón, discriminada por su género, sin igualdad educativa, laboral ni económica, dificultaba enormemente la difusión de estos principios fundamentales tanto entre los hombres como entre las propias mujeres. Durante los años treinta se demuestra que la teoría encuentra difícil acomodo en una sociedad en la que la mujer seguía siendo más un ser oprimido que compañera del varón en la lucha por la revolución social. Incluso durante la guerra, a pesar de la aparición de la figura de la miliciana, el papel de la mujer se mantiene como soporte moral o material del combatiente más que como figura indispensable de la contienda, aunque, como señala $M^{a}$ Ángeles García-Maroto, los anarquistas comprendieron que la sociedad que deseaban debía de construirse de forma equitativa entre ambos sexos. La herencia anterior es una realidad en la que la mujer no posee independencia, por lo que esta ausencia de autonomía conformaba una sexualidad femenina caracterizada por la docilidad y la mansedumbre frente al poder que representaba lo masculino ${ }^{29}$.

La transgresión de estas normas suponía la descalificación ética y moral de esas mujeres, de ahí que la existencia de un colectivo ajeno a la tradición, como el republicano y el obrerista, permite la reclamación de su propio espacio desde la seguridad de estar respaldada por dicha ideología. A partir de la Primera Guerra Mundial, con la relevancia pública de la mujer, se iban a producir cambios en el modelo de feminidad que afectarían principalmente al discurso tradicional de la domesticidad. Aunque lentamente, iba a ir incorporándose la imagen de la mujer militante que participa activamente con los hombres, incluso en acciones insurreccionales y de violencia revolucionaria durante la Segunda República. Sin embargo, entre la propia afiliación, supuestamente comprometida con estas tesis, se aprecia todavía la pervivencia de los roles tradicionales. Una consecuencia heredada de la sumisión femenina hacia el varón es la manifestación de la violencia como acción que canaliza la impotencia, generalmente del hombre, por el control tanto físico como emocional de la mujer. La reprobación pública de la discriminación sexual de la mujer persigue la adopción de una conciencia colectiva que condene la violencia doméstica y asuma necesariamente un rol activo para extirparla. Esta visión hace del cuerpo del ser amado una extensión de las voluntades del varón, siendo la mujer postergada a una posición eminentemente pasiva ${ }^{30}$.

29. García Maroto, M. A., La mujer en la prensa anarquista. España 1900-1936. Madrid, 1996; Fernández Soria, J. M., Cultura y libertad. La educación en las Juventudes Libertarias (1936-1939). Valencia, 1996; Nash, M., Mujer y movimiento obrero en España, 1931-1939. Barcelona, 1981; Rios Lloret, R. E., "Obedientes y sumisos..."; Cases Sola, A., "Mujeres rebeldes. Género, juventud y violencia política en la Segunda República". Ayer 100 (2015), pp. 73-96; Aguado, A. M., "Entre lo público y lo privado: sufragio y divorcio en la Segunda República". Ayer 60 (2005), pp. 105-134.

30. Nash, M., Mujer y movimiento obrero en España...; Nash, M., Rojas. Las mujeres republicanas en la Guerra Civil. Madrid, 2007; Nash, M., Feminidades y masculinidades: arquetipos y prácticas de género. Madrid, 2014; García Maroto, M. A., La mujer en la prensa 
Las noticias que informan de casos de violencia de género, aunque no abundan en la prensa anarcosindicalista, denuncian una realidad que se quiere mudar. La exigencia de revolucionar las conciencias pretende lograr una catarsis interna con la acumulación de situaciones intolerables en las que se censuran los males endémicos de la sociedad. Son casos como el divulgado por Vía Libre en febrero de 1937, en el que un ciudadano acusado de asesinar a su compañera sentimental se presentaba voluntariamente ante las autoridades para confesar el crimen. Ese mismo año, Gerona C.N.T. informaba del homicidio de Rosa Gallofré por parte de su novio tras una discusión sobre los zapatos que llevaba la víctima. Los ataques contra mujeres son también verbales, nuevamente manifestación de una situación de superioridad masculina como lo prueba la denuncia presentada por Concepción Solé, Juana López Campos y Modesta Roure contra un hombre por haberlas insultado de forma grosera. En otros casos, la violencia se manifiesta con un marcado sentido sexual, como lo demuestra la noticia publicada en Acracia en febrero de 1938: "Sobre el musgo de un jardín del cementerio del Sudoeste, ha sido encontrado el cadáver de una mujer completamente desnuda $[. . .]^{\prime \prime 31}$. Violencia, sexo y celos se interrelacionan en esta percepción de las relaciones en las que siempre existe un dominador y una dominada ${ }^{32}$.

La publicación de estos sucesos en la prensa libertaria no se aprovecha, sin embargo, para realizar juicios de valor o comentarios morales acerca de estos crímenes. Tampoco se condena a un género como violento, ni se ensalza al otro como víctima, sino que se dedica únicamente a informar de los acontecimientos. Son poco habituales las noticias desde una perspectiva de género como la publicada por Solidaridad Obrera en 1930 en la que se informa de un nuevo crimen "en los que la víctima es siempre la mujer a la que brutalmente quiere imponer su voluntad el hombre ${ }^{\prime \prime 33}$. En otros casos, se evidencia cierto sarcasmo en el tratamiento de la noticia que resulta de difícil comprensión por realizarse dentro de un movimiento como el libertario comprometido con la igualdad sexual, pero muy influido por su contexto cultural. En varias noticias publicadas entre junio y julio de 1937 por el mismo periódico se comunican sendos casos de denuncias de malos tratos hacia la mujer con el titular "marido cariñoso" ${ }^{\prime 34}$.

anarquista...; Espigado Tocino, M. G., "Las mujeres en el anarquismo español (1869-1939)". Ayer 45 (2002), pp. 39-72; López Santamaría, J., "El desafío de la trinidad libertaria. Feminismo y afeminismo en el seno del anarquismo hispano. El caso de las JJ.LL.", AA.VV., Las mujeres y la Guerra Civil Española: III Jornadas de Estudios Monográficos. Salamanca, 1989, pp. 88-96.

31. Acracia, 485, 14 de febrero de 1938.

32. Vía libre, 21, 20 de febrero de 1937; Gerona C.N.T., 45, 28 de julio de 1937; Acracia, 361, 21 de septiembre de 1937.

33. Solidaridad Obrera, 20, 25 de septiembre de 1930.

34. Solidaridad Obrera, 1625, 26 de junio de 1937; n$^{\circ} 1634,7$ de julio de 1937. 
La crítica sobre la subordinación de la mujer se dirige especialmente contra el Estado y la Iglesia católica, a la que se culpa directamente de haber creado esclavas cuyo único cometido es servir al hombre. Será llevada a cabo principalmente por mujeres que asumen la necesidad de denunciar públicamente la situación, lo que evidencia que la vida dentro de organizaciones libertarias como la CNT, la FAI y las JJ.LL .no era muy distinta de la que se vivía en el exterior. La prensa sirve también de plataforma para requerir tanto a las mujeres que luchen activamente por su propia emancipación, como a los hombres por impedir a sus hijas, hermanas o compañeras frecuentar los órganos confederales, obligarlas a quedarse "encerradas" en el hogar o menospreciar a las que intervenían en público en los debates dentro del sindicato. Para las militantes Antonia Fontanillas y Julia Hermosilla, la ausencia femenina en el espacio sindical se debía a la escasa motivación de muchas mujeres por los temas estrictamente ideológicos o corporativos frente a los puramente culturales. Dentro de esta predilección subyacía, como señala Eulalia Vega, la consideración profunda del sindicato como un espacio de sociabilidad masculina en el que la mujer tenía que reclamar y ganarse su sitio con ahínco. Frente al sindicato, el ateneo presentaba una mayor asistencia y participación de mujeres por ser un espacio de convivencia mixto en los que obtenían una cultura alternativa que las animaba a su propia emancipación ${ }^{35}$.

La mujer anarquista, al igual que, la protagonista de la obra de teatro de Mauro Bajatierra Como palomas sin nido, habla cuando siente necesidad de hacerlo, responde cuando quiere, se rebela contra las injusticias hacia su sexo y piensa libremente: "Perdone usted, mamá; pero la educación mía... es la tolerancia... cuando es preciso" ${ }^{\prime 36}$. En suma, las llamadas a la creación de un nuevo tipo de mujer se centran en inculcarles el interés por la cultura y el aprendizaje continuado a través de la asistencia a centros de enseñanza racionalista y hacerla partícipe de los círculos culturales libertarios. Para Galo Díez, la mujer moderna debe ocuparse de su propia liberación, cultivar su cerebro, ser buena, noble, pensadora y, sobre todo, "útil al progreso y a la causa de la humanidad de que forma parte" ${ }^{\prime 37}$. Se trata de una mujer que debe acompañar al hombre en la causa revolucionaria, asumiendo la necesidad de desprenderse de aquellos elementos femeninos que tradicionalmente le confieren debilidad para asumir un papel socialmente activo ${ }^{38}$ :

Nosotras somos las que tenemos que intervenir, como madres y compañeras, como mujeres que cansadas de sufrir viendo a nuestros seres más queridos en los presidios, azotados por los malditos esbirros, nos ponemos en los lugares de lucha,

35. Vía Libre, 13, 26 de diciembre de 1936; Pluma Libre, 16, 28 de febrero de 1937; Hombres Libres, 51, 3 de diciembre de 1937; Proa, 29, 28 de mayo de 1932; Vega, E., "Mujeres y militancia...".

36. Bajatierra, Mauro, Como palomas sin nido: comedia de tesis defendiendo el derecho íntegro de la mujer. Madrid, 1934.

37. Díez, G., La mujer en la lucha social.

38. Vía Libre, 11, 12 de diciembre de 1936. 
para ser uno más que empuñe la pistola y demostrar a nuestros compañeros que somos dignas de ellos, que donde esté su puesto estará el nuestro, que abandonamos nuestra debilidad de mujeres para en la lucha convertirnos en iguales ${ }^{39}$.

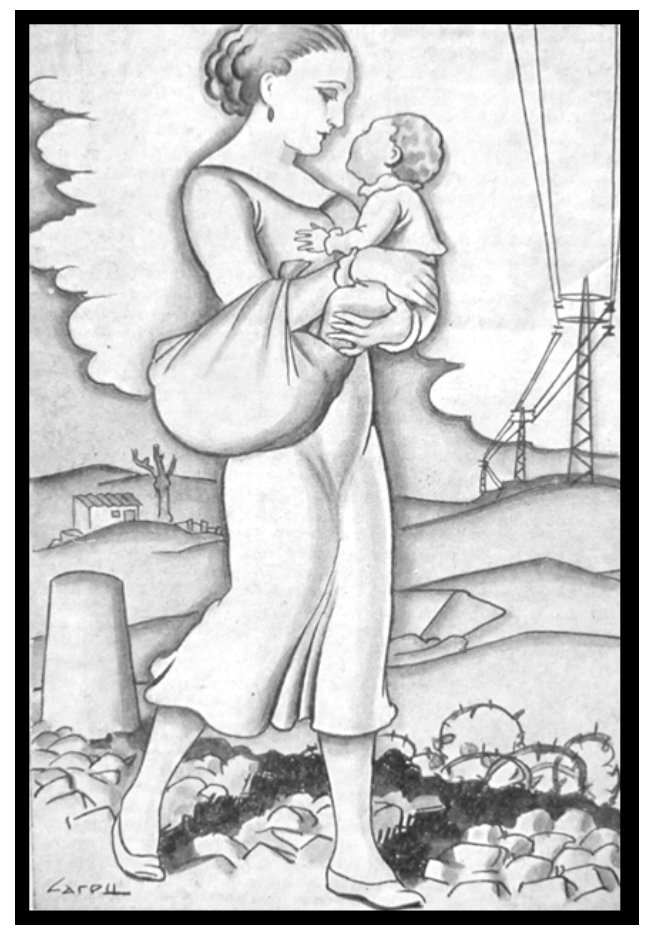

Imagen 7. Fuente: Maymón Giménez, A., El hijo del camino. Barcelona, s.d.

Al mismo tiempo, coexiste en los medios libertarios la exaltación de la maternidad como componente esencial de la acción fecundadora de la naturaleza: "Decidles, que habéis sido creadas, [...] con el fin más grande y más bello que en la naturaleza se conoce, como es la «maternidad», la voluntad del AMOR" ${ }^{\prime 4}$. Fase primordial en el desarrollo biológico de la mujer, tal concepción de la maternidad, que no se circunscribe exclusivamente al parto sino que incluye la crianza y la educación de los hijos, no es una novedad dentro del pensamiento liberal español. No se aprecia en el discurso ningún planteamiento novedoso acerca de un reparto equitativo de las tareas domésticas ni del cuidado de los hijos. Sobre la mujer recae la responsabilidad tradicional de formar a una nueva generación de individuos libres de prejuicios. Se trata de una maternidad cons-

39. Gallego García, G., En las garras de la lujuria. Barcelona, 1936.

40. Acracia, 332, 17 de agosto de 1937. 
ciente que únicamente persigue concienciar a la mujer de la responsabilidad que le otorga dicha función, pero sin revolucionar el papel tradicionalmente pasivo del hombre en la crianza o el cuidado del hogar ${ }^{41}$.

Los mensajes dirigidos al público femenino se completan con los destinados al varón, en los que se señala que el anhelo de todo buen revolucionario debe ser una mujer emancipada, no una "tradicional". Para Federico Urales, la mujer debe procurar un cambio amparado en la independencia económica frente al varón como única vía para conseguir su propia emancipación. Ana Acozar advierte en 1937 que en Cataluña, a pesar de la retórica emancipadora y de que algunas mujeres ocupan puestos de responsabilidad en la organización confederal, el hombre sigue creyéndose moralmente superior. Militantes como Pepa Carpena o Pura Pérez padecieron los comportamientos de una militancia masculina que, incluso en las JJ.LL., se mofaba de la presencia de mujeres en sus reuniones. Militantes como Fausto Brand abogan porque la mujer no pierda su "encanto femenil" en su incorporación al mundo laboral como elemento de belleza más que como compañera en el trabajo. El anarcosindicalista gallego señala que su presencia es mucho más útil en la esfera doméstica que fuera de ella, pues un trabajo excesivo puede poner en riesgo su salud y lastrar su función maternal. Lucía Sánchez Saornil critica este pensamiento de raíz biologicista y conservador que convierte a la mujer en un ser únicamente destinado a tener hijos ${ }^{42}$ :

Así como el antiguo señor, hoy burgués, cree que los obreros que trabajan por su cuenta y que están a su servicio, son sus vasallos, así, también, los hombres, aun los que nos creemos emancipados, estiman

41. Sobre la apelación a las virtudes femeninas tradicionales: Brazo y Cerebro, 13, 15 de noviembre de 1935; Solidaridad Obrera, 130, 8 de julio de 1933; Ríos Lloret, R. E., "Obedientes y sumisos: sexualidad femenina en el imaginario masculino de la España de la Restauración". Ayer 63 (2006), pp. 187-209; Sánchez Ortega, M. H., Pecadoras de verano arrepentidas en invierno. Madrid, 1995; Aresti Esteban, N., "Cuestión de dignidad. Género, feminismo y culturas políticas", Forcadell Álvarez y Suárez Cortina, La Restauración y la República: 1874-1936. Madrid, 2015, pp. 85-110; Espigado Tocino, M. G., "Placer, sexualidad y maternidad", Muñoz Muñoz, Gregorio Gil y Sánchez Espinosa, Cuerpos de mujeres: miradas, representaciones e identidades. Granada, 2007, pp. 329-334; Aguado, A. M., "Cultura socialista, ciudadanía y feminismo en la España de los años veinte y treinta". Historia Social 67 (2010), pp. 131-153; Yusta Rodrigo, M., "Género y antifascismo en España. De la II ${ }^{a}$ República a la Guerra Fría (1931-1950)", Anuario IEHS: Instituto de Estudios histórico sociales. Buenos Aires 2013, pp. 227-247; Ramos Palomo, M. D., "La construcción cultural de la feminidad en España. Desde el fin del siglo XIX a los locos y politizados años veinte y treinta", Nash, Feminidades y masculinidades: arquetipos y prácticas de género. Madrid, 2014, pp. 21-46.

42. Gerona C.N.T., 79, 5 de septiembre de 1937; La Revista Blanca, 102, 15 de agosto de 1927; Vía Libre, 20, 13 de febrero de 1937; Solidaridad Obrera, 81, 20 de febrero de 1931; Solidaridad Obrera, 205, 16 de julio de 1931; Solidaridad Obrera, 118, 15 de abril de 1933; Solidaridad Obrera, 1901, 15 de octubre de 1935; Nash, M., Mujeres Libres: España 1936-1939. Barcelona, 1975; Ackelsberg, M., Mujeres Libres. El anarquismo y la lucha por la emancipación de las mujeres. Barcelona, 1999. 
que la mujer ha nacido para servir a los hombres, y que a este servicio que limitada su misión ${ }^{43}$.

Esta realidad denota que los comportamientos tradicionales seguían inalterables en el seno de un movimiento mayoritariamente formado por hombres, que cristalizó en la extensión de una imagen dual de la mujer. La necesidad de rebelarse contra las formas tradicionales de sumisión confluía al mismo tiempo con la responsabilidad de ser madre, educadora y dueña del hogar. La peculiaridad reside en la coexistencia de varios discursos, tanto conservadores como progresistas, todos aceptados como válidos al otorgar a la mujer la elección de su propio destino, siempre que los condicionantes sociales lo permitieran. La solución a la problemática de la mujer debía pasar, en opinión de Sánchez Saornil, por un proceso de modificación conceptual de qué es y qué representa la mujer. Evidentemente, la anarquista madrileña dirige su discurso hacia el militante varón, pero sin olvidar que es la mujer la que debe reivindicar su espacio, y esto únicamente sería posible mediante la asunción de una nueva concepción de sí misma ${ }^{44}$.

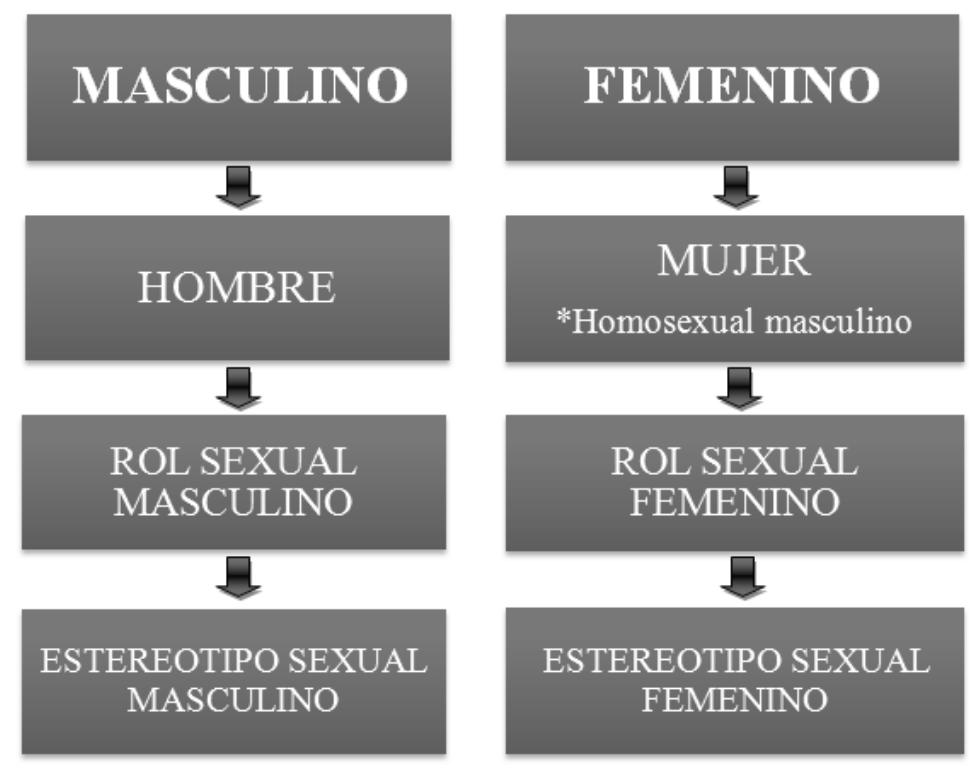

Cuadro I. Perspectiva sexual tradicional que asocia el sexo al género. Fuente: Fernández Sánchez, J., Nuevas perspectivas en la medida de masculinidad y feminidad. Madrid, 1983. Elaboración propia.

43. La Revista Blanca, 267, 1 de marzo de 1934.

44. Solidaridad Obrera, 1080, 2 de octubre de 1935; García Maroto, M. A., La mujer en la prensa anarquista. España 1900-1936. Madrid, 1996. 
La visión ontológica del anarquismo, en el caso del hombre, se orienta a su configuración conforme a postulados modernos basados en el cultivo de facultades sociales y morales que le permitiesen comportarse de forma ética. La crítica a la sociedad demanda la renuncia de su tradicional posición de dominio y control sobre la mujer para reconocerla como compañera y amiga. Pero la ambivalencia marca un discurso que deja entrever el mantenimiento del papel paternal del varón respecto a su hija, madre o compañera sentimental, al conservar la posición de impulsor del estudio, la elevación ética y el enriquecimiento personal de la mujer. Esta imagen se traslada al mundo literario y se convierte en un tópico recurrente, como se muestra en la obra de Gregorio Gallego, en la que Violeta, "víctima" de la sociedad burguesa, agradece a Víctor, militante de las JJLL y su "salvador", su apoyo incondicional:

-¡Qué buenos eres, Víctor! Cuando ya notaba que las fuerzas me abandonaban para seguir luchando contra esa burguesía que cada día me hacía más imposible la vida, tú, noble y leal, me ofreces la mano para desafiar a todos los que pretendían hundirme en el río fangoso de la prostitución ${ }^{45}$.

Víctor representa al hombre que se comporta de forma activa y se deja guiar por sus sentimientos, previamente equilibrados por el cultivo de las ideas de razón y justicia. En palabras de Alejandro G. Gilabert: "No deberíamos ser los hombres quienes las libertáramos. Con ayudarlas basta. Que se entrenen en la lucha, ya que la lucha templa las almas y las predispone para los duros combates y las gestas más bellas" ${ }^{\prime 4}$. El hombre anarquista, consciente de la condición de esclavitud de la mujer, defiende que debe dejarse que esta alcance por sus propios medios la autonomía necesaria para ser completamente libre. En el fondo se manifiesta el triunfo del género como elemento que divide más que une, permitiendo que el varón se acomode en su situación dominante, mientras la mujer no asume el control real sobre su propio ser ${ }^{47}$.

La necesidad de un hombre nuevo como un ser racional y sensible estaba lastrada por la persistencia de una moral masculinizada transmitida de generación en generación. En una sociedad donde género y sexo se funden dentro de un tipo prefijado de individuo, ser hombre o mujer está condicionado, tanto por el sexo como por los roles sociales asociados a cada uno de ellos (profesión, indumentaria, gustos, carácter espiritual, etc.). Esta interpretación se encontraba respaldada por las tesis de Gregorio Marañón, uno de los médicos más reconocidos de la época, para el que las características que definían lo masculino y lo femenino estaban relacionadas con la diferenciación sexual propia de cada

45. Gallego García, G., En las garras de la lujuria.

46. Tierra y Libertad, 6, 28 de marzo de 1931.

47. Solidaridad, 6, 3 de agosto de 1935. 
sexo. La influencia hormonal o genital era fundamental para la conformación del hombre o la mujer desde su perspectiva psicológica. Incluso, Marañón plantea en su ensayo Sexo, trabajo y deporte los distintos cometidos sociales que corresponderían a hombres y mujeres. Estos argumentos permiten afianzar en el imaginario colectivo la estrecha relación existente entre género y sexo, al tiempo que se combina la defensa de la igualdad de los sexos no sólo desde una óptica filosófica, sino también desde una perspectiva científico-médica que establece la diferencia en términos de igualdad ${ }^{48}$.

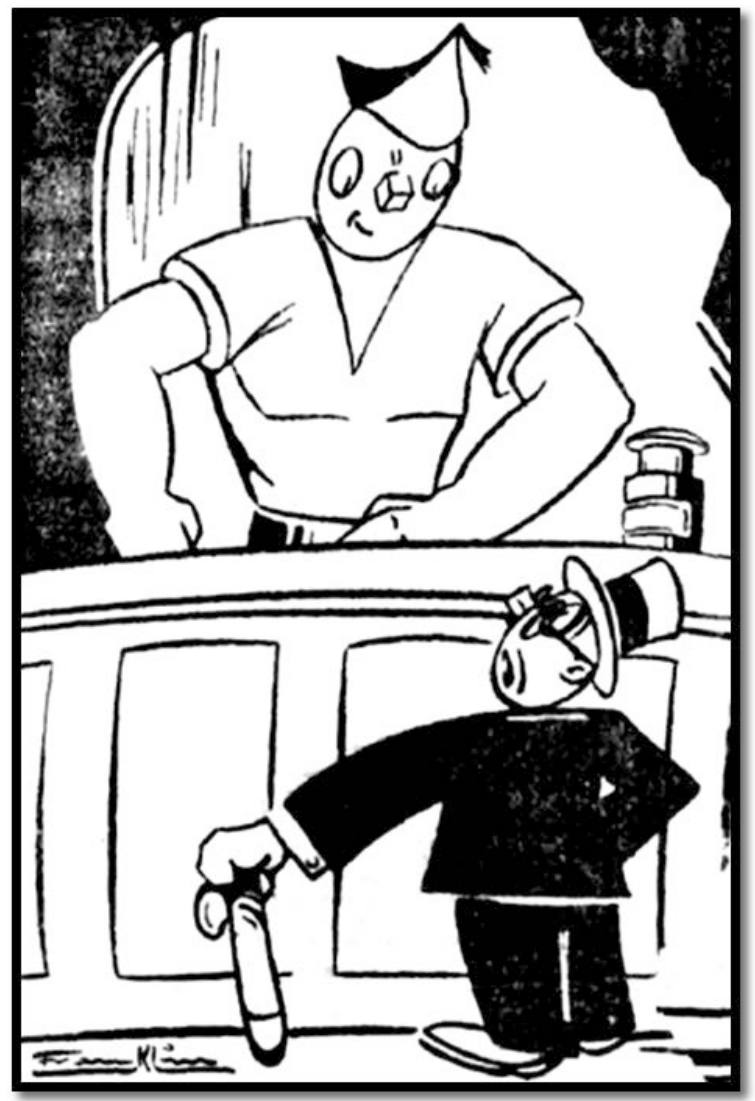

IMAGEN 8. Fuente: Solidaridad Obrera, 1664,

17 de agosto de 1937.

48. Ugarte Pérez, F. J., "La matriz del deseo: del género a lo genital”. Ayer 87 (2012), pp. 23-44; Castejón Bolea, R., "Marañón y la identidad sexual. Biología, sexualidad y género en la España de la década de 1920". Arbor 759 (2013); Balaguer i Perigüell, E., "Marañón y la medicina en España". Arbor 759 (2013). 
A pesar de la educación fomentada desde los centros de divulgación libertarios (ateneos, sindicatos o grupos de acción), muchos militantes acaban transmitiendo de forma inconsciente roles y comportamientos de género desde una perspectiva sexualizadora. La virilidad, como virtud, forma parte de la cultura política de los españoles y se mantiene en la retórica ácrata. Es lo que Raewyn Connell denomina "masculinidad hegemónica", al ser la concepción dominante de una sociedad y un momento histórico determinado. Este choque entre modernidad y tradición es especialmente notable en cuestiones relativas a las esferas particulares de ambos sexos. El discurso de los años treinta, especialmente durante los años de la Guerra Civil, está impregnado de una impronta masculina que persigue el ensalzamiento de lo varonil desde la exaltación de lo sexual. Estos mensajes interpretan la virilidad como atributo exclusivo del hombre y sinónimo de fortaleza, fuerza, acción, sacrificio, rebeldía o potencia ${ }^{49}$.

El hombre moderno para el anarquismo es aquel que tiene y defiende unos ideales firmes e imperecederos. Como Julián, el protagonista de la novela El último baluarte de Francisco Caro Crespo: "un hombre muy hombre" ${ }^{\text {"50. }}$. Debe ser un individuo activo que combate las injusticias sociales que le ha tocado vivir a través de un comportamiento ejemplar que emana del orden moral de unas ideas y sentimientos que son el sustento de su acción pública. Muchos propagandistas se dejan llevar en sus escritos por estereotipos ligados especialmente a la tradición cultural. Rizal Robert habla de "viril movimiento social", Vicente Turón de "gesto viril", Miguel Giménez Igualada de "valor varonil" y "cerebros viriles", Juan Santana Calero señala la revolución exige "virilidad y transformación" y Ramón Liarte ensalza la figura póstuma de Buenaventura Durruti como "símbolo de un pueblo macho" ${ }^{\text {"1 }}$. Todo comportamiento contrario al tópico viril es criticado, hasta el punto de achacar a aquellos individuos una ausencia total de masculinidad como un lastre a su condición de hombre: "La F.A.I. no puede ni admite en su seno a los degenerados, tanto si lo son moralmente como físicamente. La Federación Anarquista Ibérica, sólo llama a HOMBRES que sean muy HOMBRES, no importando la edad"52. En contraposición, lo relacionado con la femineidad -debilidad, delicadeza, pasión o pasividad- es un atributo

49. Connell, R., Gender and power. Stanford, 1987; Buchbinder, D., Masculinities and identities. Melbourne, 1994; Aresti Esteban, N., Masculinidades en tela de juicio: hombre y género en el primer tercio del siglo XX. Madrid, 2010; 2014; Aresti Esteban, N., "Masculinidad y nación en la España de los años 1920 y 1930", Mélanges de la Casa de Velázquez. Madrid 2012, pp. 55-72; Fernández-Llébrez González, F., “¿Hombres de verdad?: estereotipo masculino, relaciones entre los géneros y ciudadanía". Foro Interno 4 (2004), pp. 15-44.

50. Caro Crespo, F., El último baluarte. Barcelona, s.d.

51. La Colmena Obrera, 6, 6 de diciembre de 1931; Nosotros, 2, 1 de noviembre de 1937; Hombres Libres, 58, 4 de febrero de 1938; El Frente, 142, 21 de noviembre de 1937.

52. Vida Nueva, 310, 18 de octubre de 1937. 
que disminuye la esencia masculina del varón y lo degrada como persona: "Sin lamentos, como hombres" ${ }^{\prime \prime 3}$.

La utilización de términos como "invertido" y "pervertido" sitúa a los propagandistas como sostenedores involuntarios de comportamientos tradicionales que no han desterrado conforme manda el ideal. El uso ofensivo y descalificatorio de estas expresiones sirve para atacar y desprestigiar también ante la militancia a los "enemigos" tradicionales de los libertarios -clérigos, políticos y militares-: "Hagamos esto antes de que sea tarde y no lamentemos como mujerucas lo que no supimos evitar como hombres [... $]^{\prime \prime 54}$. Estos ejemplos demuestran que los roles de género, como conductas aprendidas culturalmente, aunque pueden ser modificados, se mantenían intactos en el subconsciente de muchos libertarios que los transmitían a las nuevas generaciones. A pesar de emplazar a la militancia a la defensa de la igualdad entre hombres y mujeres, en la práctica, lo masculino y lo femenino eran categorías estancas separadas, más relacionadas con la moral tradicional que con el discurso libertario. Este adolece de la comprensión acerca del significado cambiante que tiene ser hombre y mujer a lo largo de la historia y muestra la lentitud con la que se aprehenden e interiorizan los postulados morales ${ }^{55}$.

\section{Conclusiones}

El presente artículo analiza la visión ontológica desarrollada por el anarquismo español en su intento por configurar una imagen del ser capaz de servir como modelo futuro del tipo de individuo que se quiere alcanzar. Idealismo que cuenta con un pensamiento de corte materialista y pragmático que sitúa lo cultural en el centro del debate sobre lo que es ser anarquista. Esta configuración prototípica está relacionada con los principios fundamentales del anarquismo desde finales del siglo XIX como son los conceptos de naturaleza, ciencia, progreso y razón. En este sentido, la naturaleza ocupa un lugar central en la cosmovisión ácrata ya que su existencia vertebra un pensamiento que ensalza lo natural como esencia de vida y se convierte en referencia básica para justificar el tipo de sociedad que se persigue. La teoría de la evolución se inserta dentro de esta noción de avance progresivo de la humanidad porque acredita la idea de la mejora de la especie desde sus orígenes. Se confía en el éxito de la revolución para la eclosión definitiva de la Anarquía, vislumbrada como un acto de fuerza que acelera el ritmo habitualmente lento del progreso natural.

53. Solidaridad C.N.T./A.I.T., 40, 28 de marzo de 1936.

54. Acracia, 484, 12 de febrero de 1938.

55. Vía libre, 8, 21 de noviembre de 1936; Inquietudes, 2, 21 de julio de 1934. El tratamiento anarquista de la homosexualidad se abordará más adelante en el apartado correspondiente, dado que el anarquismo nunca la consideró una opción real de comportamiento, ni tampoco una conducta deseable, sino que la inserta dentro de las formas humanas de sexualidad. 
En este organigrama mental, el ser humano ocupa una posición relevante como especie dominante para actuar en nombre de la naturaleza en la esfera social, situándose su significación en la posesión del don de la racionalidad. Su encumbramiento como especie hace que el discurso se centre en el género y no en el sexo, hecho que permite abogar por la igualdad entre hombres y mujeres como vía de progreso.

Sobre este nuevo ser recae una enorme presión moral porque al tiempo que se rechaza el innatismo de la maldad, se culpabiliza al medio social y al Estado de pervertir al individuo, por lo que la educación se perfila como el motor indispensable para crear al ciudadano responsable y solidario capaz de vivir armónicamente en sociedad. Este ser completo estaría formado por ambos sexos, cada uno independiente entre sí pero ontológicamente inseparables. Por un lado, la mujer que se encuentra ante una realidad social marcada por la desigualdad de género que hace que asuma de forma autónoma la lucha por su emancipación. En ella converge tanto el discurso tradicional, que la representa como madre y cuidadora, como el que la concibe como mujer independiente y compañera del varón en la lucha social. Y por otro, el hombre al que se le conmina a aceptar a la fémina como compañera en el trabajo pero sin incentivarlo a modificar los tópicos tradicionales que identifican lo masculino como sinónimo de fuerza-vigor-rebeldía, y lo femenino como sensibilidad-debilidad-pasividad. Sin embargo, la pervivencia del discurso tradicional demuestra que los conceptos de masculinidad y feminidad tradicionales son difíciles de erradicar en una sociedad iletrada en la que dichas construcciones culturales, inculcadas desde la infancia, permanecen en muchos individuos inalterables a pesar de su adscripción ideológica a siglas revolucionarias. 